\title{
MATISSE: an ArcGIS tool for monitoring and nowcasting meteorological hazards
}

\author{
V. Rillo ${ }^{1}$, A. L. Zollo ${ }^{1,2}$, and P. Mercogliano ${ }^{1,2}$ \\ ${ }^{1}$ Regional Models and geo-Hydrological Impacts Division, CMCC - EuroMediterranean Centre on Climate \\ Change, Capua (CE), Italy \\ ${ }^{2}$ Meteo Systems and Instrumentation Laboratory, CIRA - Italian Aerospace Research Centre, Capua (CE), Italy \\ Correspondence to: A. L. Zollo (a.zollo@cira.it)
}

Received: 14 January 2015 - Revised: 29 June 2015 - Accepted: 01 July 2015 - Published: 14 July 2015

\begin{abstract}
Adverse meteorological conditions are one of the major causes of accidents in aviation, resulting in substantial human and economic losses. For this reason it is crucial to monitor and early forecast high impact weather events. In this context, CIRA (Italian Aerospace Research Center) has implemented MATISSE (Meteorological AviaTIon Supporting SystEm), an ArcGIS Desktop Plug-in able to detect and forecast meteorological aviation hazards over European airports, using different sources of meteorological data (synoptic information, satellite data, numerical weather prediction models data). MATISSE presents a graphical interface allowing the user to select and visualize such meteorological conditions over an area or an airport of interest. The system also implements different tools for nowcasting of meteorological hazards and for the statistical characterization of typical adverse weather conditions for the airport selected.
\end{abstract}

\section{Introduction}

Monitoring and nowcasting adverse meteorological conditions are crucial for the safety and optimization of all flight phases, especially for small aircraft or unmanned vehicles that are not equipped with adequate instrumentation. Indeed, adverse weather conditions constitute a major factor causing aviation accidents (Kulesa, 2003; Krozel et al., 2008). For these reasons numerous projects, such as FLYSAFE (Tafferner et al., 2008), SPADE (Van Eenige and Muehlhausen, 2006), EWENT (Juga and Vajda, 2012) and WxFusion (Gerz et al., 2012), as well as systems such as XMWX (Snyder and Patsiokas, 2004), AWARE (Ruokangas et al., 2006) and AWDSS (Barrere Jr. et al., 2008), have been developed to increase pilots' awareness of inflight meteorological conditions (so-called weather awareness). In this context the Italian Aerospace Research Center (CIRA) has developed MATISSE (Meteorological AviaTIon Supporting SystEm), an ArcGIS tool for monitoring and nowcasting meteorological hazards, developed using the ArcGIS development environment ArcObjects. The system differs from existing ones in its ability to gather data from different sources (e.g. remote sensing platforms, meteorological center archives, outputs of numerical weather prediction models), handling data of different formats and providing information on monitored and forecasted meteorological conditions in formats tailored to pilots' needs. In addition, it includes innovative nowcasting tools and algorithms able to retrieve information on meteorological parameters and hazards from website images.

A system which presents numerous analogies with MATISSE is Synergie, a weather expertise and forecasting system developed in collaboration with Meteo France experts. Like MATISSE, it integrates meteorological data in an automatic and near real time way from various sources and ensures easy access to data, providing maps and charts. The main difference between the two systems lies in the fact that MATISSE was conceived for aviation purposes, focusing on aviation weather hazards and reporting on board only information relevant to the flight.

The present work is the expanded version of Rillo et al. (2014), including additional functionalities that have been implemented in the system, focusing on nowcasting tools and outlining the context in which the system is placed. The pa- 


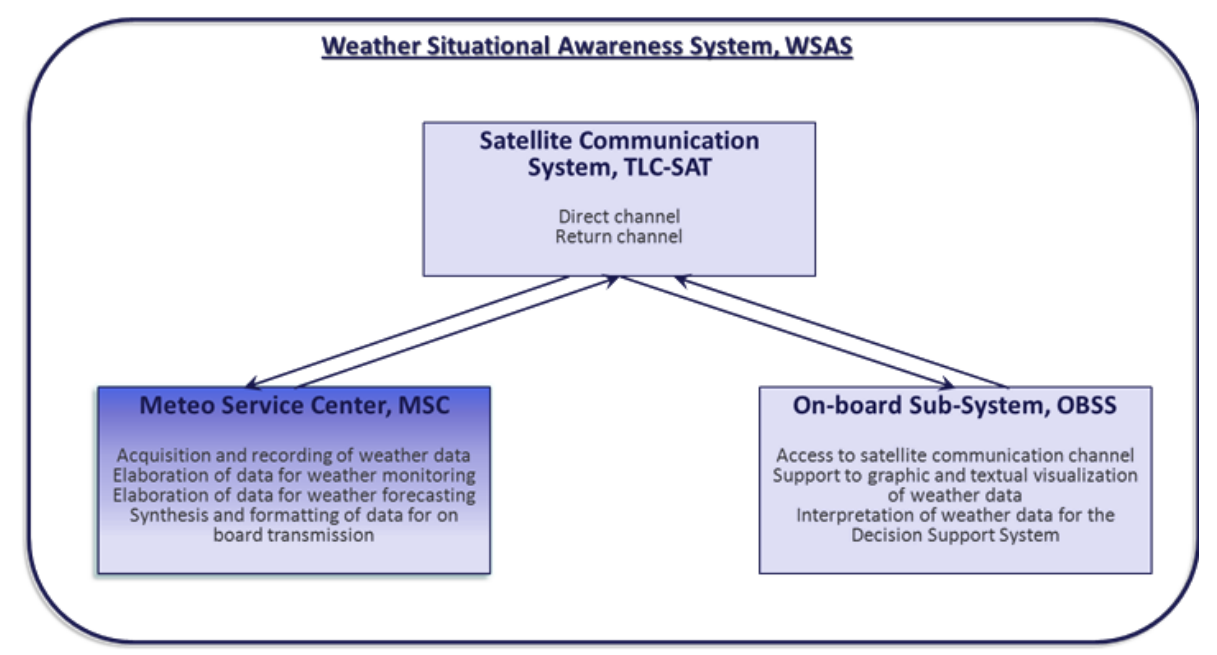

Figure 1. Weather Situational Awareness System block diagram.

per is organized as follows: an overview of the system architecture is proposed, followed by a description of MATISSE input data and of the outputs and functionalities provided to users.

\section{Overall system overview}

In the framework of the CIRA project TECVOL II (TECnologie per il VOLo autonomo - technologies for autonomous flight) founded by MIUR (Italian Ministry of Education, University and Research), aiming to develop technologies to support pilots of Personal Air Vehicles (PAVs) or automated systems of Unmanned Air Vehicles (UAVs), CIRA is developing the Weather Situational Awareness System (WSAS), a system able to provide real time data for updating mission management and trajectory generation functions (for UAVs) and for enhancing pilots' awareness of the meteorological conditions occurring during the flight (for PAVs). As shown in Fig. 1, the WSAS consists of three blocks: an on-board segment (On-Board Sub-System, OBSS), a ground segment (Meteo Service Center, MSC) and a satellite link between them (Satellite Communication System, TLC-SAT).

The ground segment MSC represents the core of the entire system because it gathers, processes and integrates observational data and forecasts from meteorological center archives and CIRA weather stations. Such data are formatted in order to be transmitted to the On-Board Sub-System using the Satellite Communication System. The on-board segment OBSS accesses the satellite communication channel and supports the graphical and textual visualization of the weather data provided by the ground segment and data provided by sensors installed on board. Visualization will be carried out using tablets, laptops or multi-functional displays integrated into the cockpit. The Satellite Communication System pro- vides a bidirectional link between the ground segment and the on-board segment using a direct and a return channel.

Within this architecture, MATISSE is the system that accomplishes most of the MSC functionalities by processing and storing raw data collected by the MSC and providing user-friendly information for the detection and forecast of meteorological hazards. Indeed, the system processes meteorological data from different sources (in situ and remote sensing measurements, outputs of numerical weather prediction models, websites), available in different formats (e.g. BUFR, NetCDF, GRIB2, HDF) and stores them in a geodatabase. After storage the meteorological variables can be further elaborated in order to obtain more complex information and provide user-friendly maps, graphs and statistics.

Users can retrieve the information of interest using the MATISSE graphical interface shown in Fig. 2. Different selections on the graphical elements produce SQL (Structured Query Languages) queries to geodatabase able to extract the desired information and to visualize maps, statistics and files of the desired information. MATISSE mainly aims to support flights of PAVs and UAVs. That said, these two kinds of vehicles have different characteristics and of course different "needs". Specifically, in the case of PAVs, graphical visualization of detected hazards could be useful for pilots, while for UAVs (unmanned), graphical information is unnecessary. However, in this case a text file reporting aviation hazard locations and corresponding hazard levels could be of great benefit since such weather information could be fed into on-board Decision Support Systems (DSS), the tool employed on UAVs to improve on-board situational awareness autonomously. In order to take such different needs into account, MATISSE is a very versatile tool since it offers several functionalities that, depending on the case, adapt to different user requirements. 


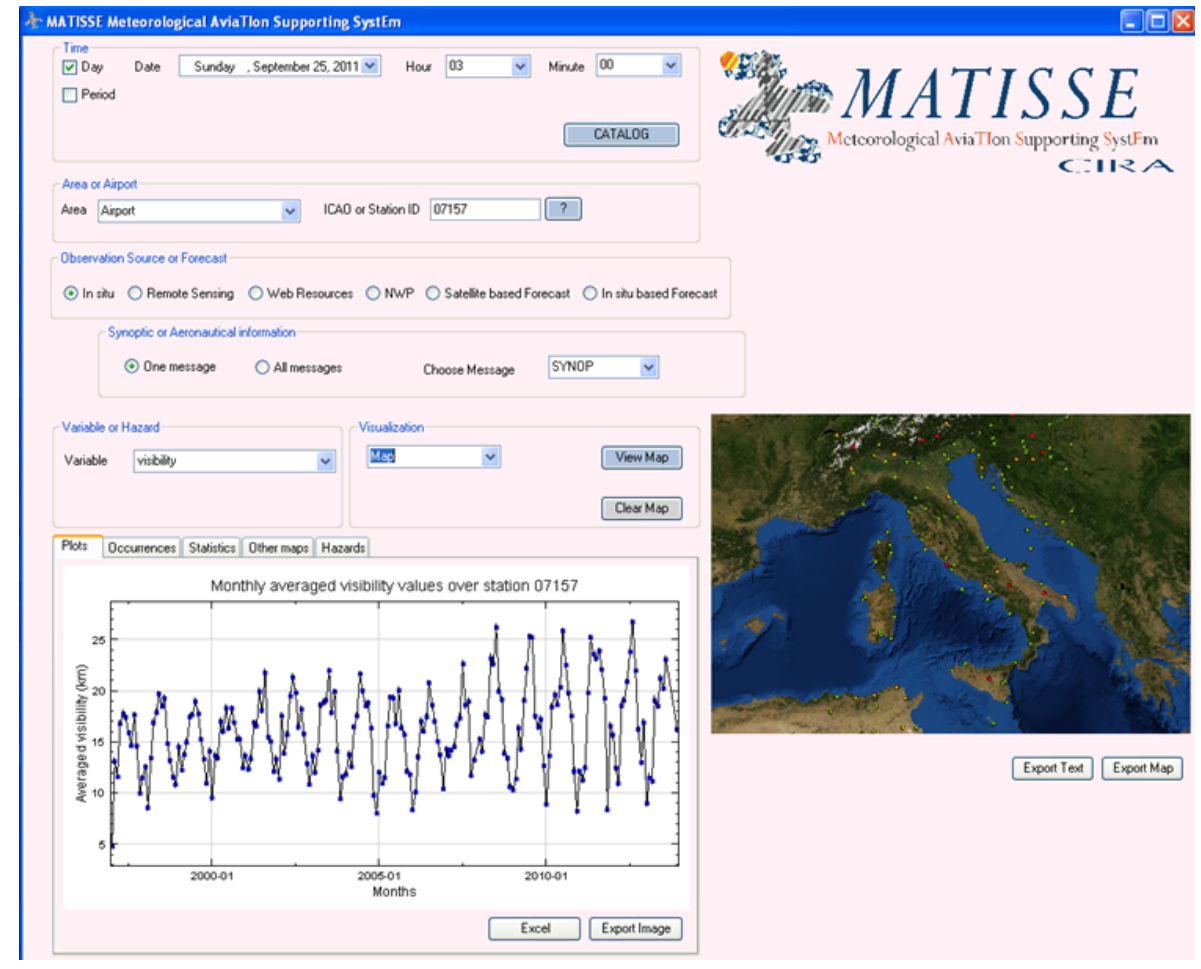

Figure 2. MATISSE graphical interface.

\section{Sources of meteorological data}

As described above, MATISSE accesses the database containing observed and forecasted meteorological data. In the following section the main features of the imported data are reported.

\subsection{Observed data}

Thanks to the agreement of CIRA with the Italian Air Force meteorological service, the observed input data are mainly provided by the ECMWF MARS Archive (Hennessy, 1986), an archive making weather data available from stations located all over the world, comprising AIREP data, vertical soundings data (TEMP and PILOT), land surface data (SYNOP and METAR) and sea surface data (SHIP). Such data are available in BUFR (Binary Universal Form for the Representation of meteorological data) format and converted into text files in order to be imported into the database. The data can be used to extract numerous meteorological variables (e.g. visibility, wind speeds and directions, present and past weathers, temperatures, cloud cover, three-hour pressure change), to be visualized or further elaborated. Similarly, MATISSE downloads the latest METARs and TAFs from the Italian Air Force website and converts and imports them into the database.

Additional observed input data are provided by the Meteosat Second Generation (MSG) satellite (Schmetz et al.,
2002). Indeed, MSG data (EUMETSAT, 2007), available in HDF (Hierarchical Data Format) format, have been processed in Matlab for the detection of convective clouds (clouds responsible for the presence of thunderstorms, turbulence, wind shear and icing phenomena) and EUMETSAT products have been elaborated to detect various meteorological hazards for aviation (such as turbulence, icing, snow, cumulonimbus clouds, intense rainfall and volcanic ash) (EUMETSAT, 2011). In particular, three EUMETSAT products have been used: Multisensor Precipitation Estimate (MPE) (Heinemann et al., 2002), Cloud Analysis (CLA) (Lutz et al., 2003) and Atmospheric Motion Vectors (AMV) (Holmlund, 2002).

MPE provides an estimate of precipitation rates observed from satellite and occurring over Europe; CLA provides a classification of types, phases and depths of clouds observed from satellite. Indeed, cloud phases are used in order to detect areas affected by icing conditions (hazardous due to the formation of ice on aircraft walls and instruments). Finally, AMV provides wind speeds and directions, at different pressures, observed from satellite. After the conversion of these products from raw format into text files, they are imported into the database accessed by MATISSE.

In addition, MATISSE recovers information on missing meteorological parameters from free images available on the internet. For example, due to the unavailability of radar data at CIRA, it accesses the Italian Civil Protection website and downloads and visualizes the latest radar image over Italy. 
In order to overcome the current lack of raw data, MATISSE implements tools able to retrieve missing meteorological information from free images available on the internet. Current developments concern a tool able to obtain timing and location of lightning flashes over Europe from Blitzortung.org website images and report such information in a text file that can be imported into the geodatabase.

\subsection{Forecast data}

As previously described, MATISSE is able to handle not only observed data but also outputs of numerical models (forecasting and nowcasting). Forecast data from the COSMO LM model (Doms and Schättler, 2002) at 7 and $2.8 \mathrm{~km}$ resolutions are available in MATISSE thanks to the implemented function able to report NetCDF files in a Comma-Separated Value (CSV) format and to store them in the geodatabase. At present, this function has been implemented only for such a limited area model. However, it will be extended in the future to include further forecast models.

In addition MATISSE implements two tools for nowcasting precipitation and the evolution of convective cloud nuclei, i.e. the convective cores inside cloud systems. The former is carried out by applying the uniform advection technique (Austin and Bellon, 1974) to the MPE product. This technique assumes that the precipitation field moves at a uniform and constant velocity and that there are no changes in the rainfall rates during the forecast. As a consequence, a preliminary estimate of the velocity of the precipitation field is computed by evaluating the cross correlations between two consecutive observations. Indeed, the algorithm computes the cross correlations between them for all the possible displacements and chooses the spatial shift that maximizes the correlation. The forecast is obtained by moving the observed precipitation field according to the estimated shift, assuming that the field velocity is constant during the lead time (time interval occurring between the observation time and the forecast one). This technique is used to provide forecasts in text format that can be imported into the database.

The second nowcasting tool is based on MSG-2 data and is able to provide $15 \mathrm{~min}$ forecasts of the evolution of convective cloud nuclei. First of all, the algorithm detects the presence of convective clouds using the infrared brightness temperature and identifies cloud nuclei. It then compares the brightness temperatures in the infrared and water vapor channels of two consecutive satellite images forecasting the developing or dissolving of convective cloud nuclei in the following 15 min (Puca et al., 2005).

\section{MATISSE outputs}

Starting from the meteorological variables stored in the database, MATISSE provides various outputs that will be described below.

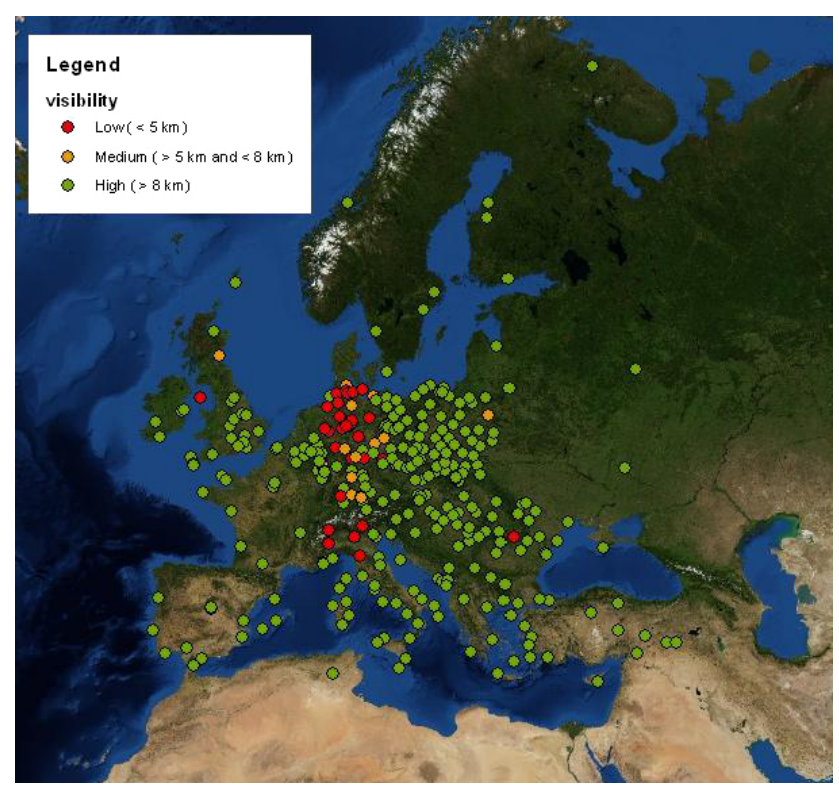

Figure 3. Visibility conditions (km) occurring 05 September 2011, 02:30 UTC.

\subsection{Observed and forecasted maps}

The main goal of the system is to provide an immediate and concise representation of weather conditions observed or forecasted, with special emphasis on hazards. Such concise representation is provided with maps or text files reporting the risk areas in order to supply only the relevant information during the route or combining different hazards on the same map. For this reason, MATISSE provides maps in a GIS environment displaying the meteorological variables and, in all cases, their corresponding hazard levels with different colors. For instance, in Fig. 3 an observed visibility map is shown: airports with visibility below $5 \mathrm{~km}$ are displayed with red dots, airports with visibility between 5 and $8 \mathrm{~km}$ are reported with orange dots and airports whose visibility exceeds $8 \mathrm{~km}$ are reported with green dots. Another example is shown in Fig. 4 in which areas with the presence of icing conditions are marked in blue.

An additional function of the system allows overlapping of meteorological variables in order to display multiple hazards on a single map. An example is reported in Fig. 5 in which lightning flashes, strong winds and convective clouds are visualized together.

In order to provide a synthetic representation of the meteorological conditions, MATISSE allows potentially hazardous areas to be reported as rectangles in order to reduce the information content to be transmitted on board, representing only the four vertexes of the areas with the presence of meteorological hazards. Indeed, the system implements algorithms able to identify so-called blobs (areas that are homogeneous in terms of specific characteristics, Carson et al., 1999) and include them in rectangles. For instance, in Fig. 6 the con- 


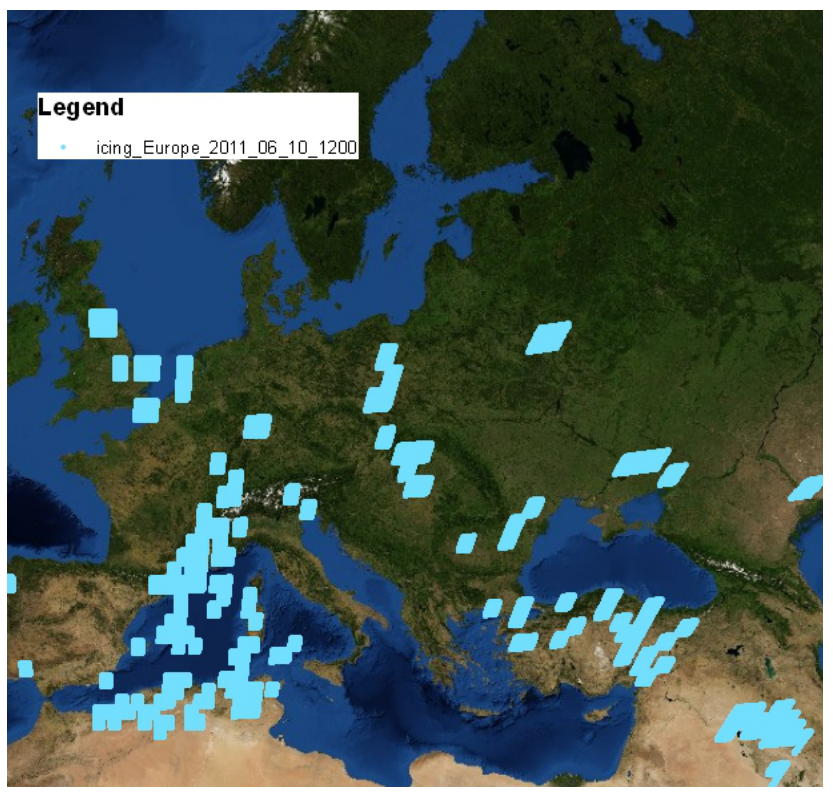

Figure 4. Icing conditions occurring 10 June 2011, 12:00 UTC.

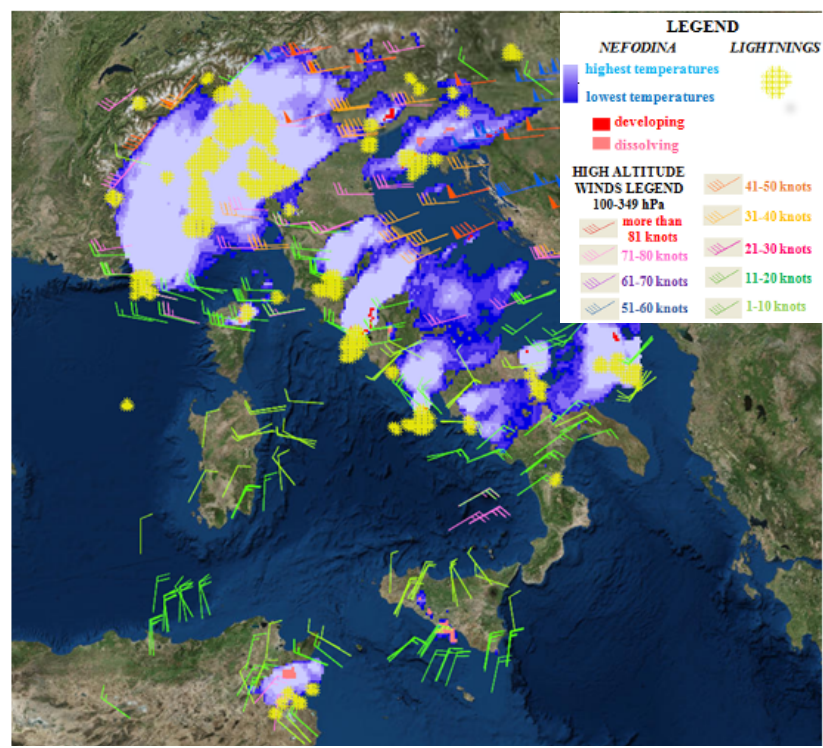

Figure 5. Overlapping of strong winds, convective clouds and lightning occurring 14 June 2014, 17:00 UTC.

vective clouds observed during 28 July 2011 at 17:45 UTC are reported as rectangles.

On the other hand, MATISSE is able to display maps of outputs of the convective cloud nowcasting tool (see Rillo et al., 2014), precipitation nowcasting tool (Fig. 7) and the COSMO LM model (Fig. 8). All these maps can be exported in Excel files in order to be further elaborated by users.

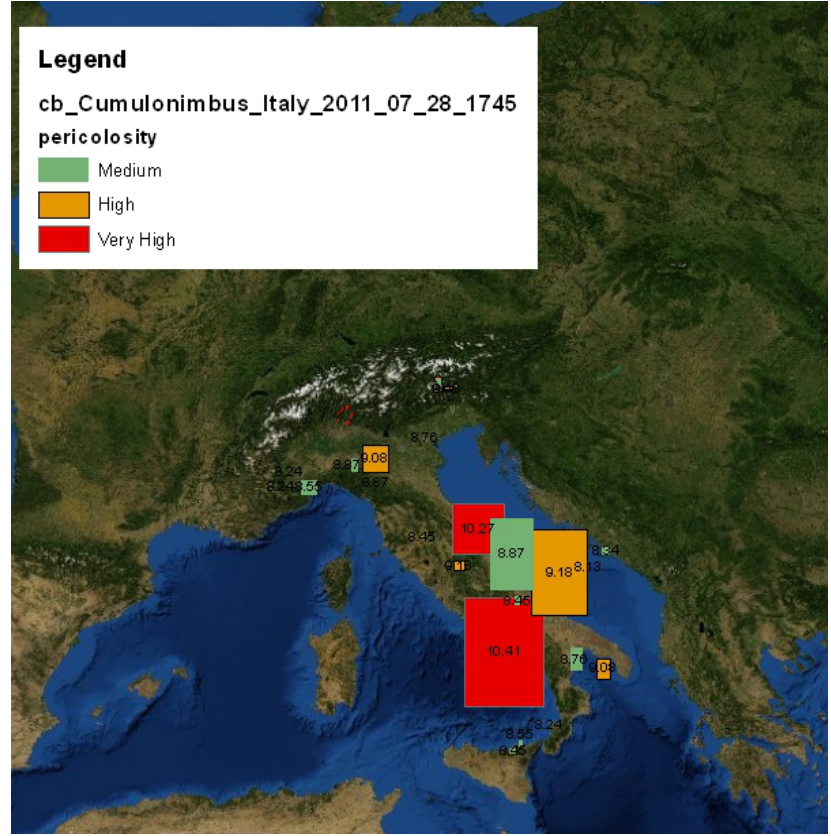

Figure 6. Rectangles representing convective clouds (and their corresponding hazard levels and heights) occurring 28 July 2011, 17:45 UTC.

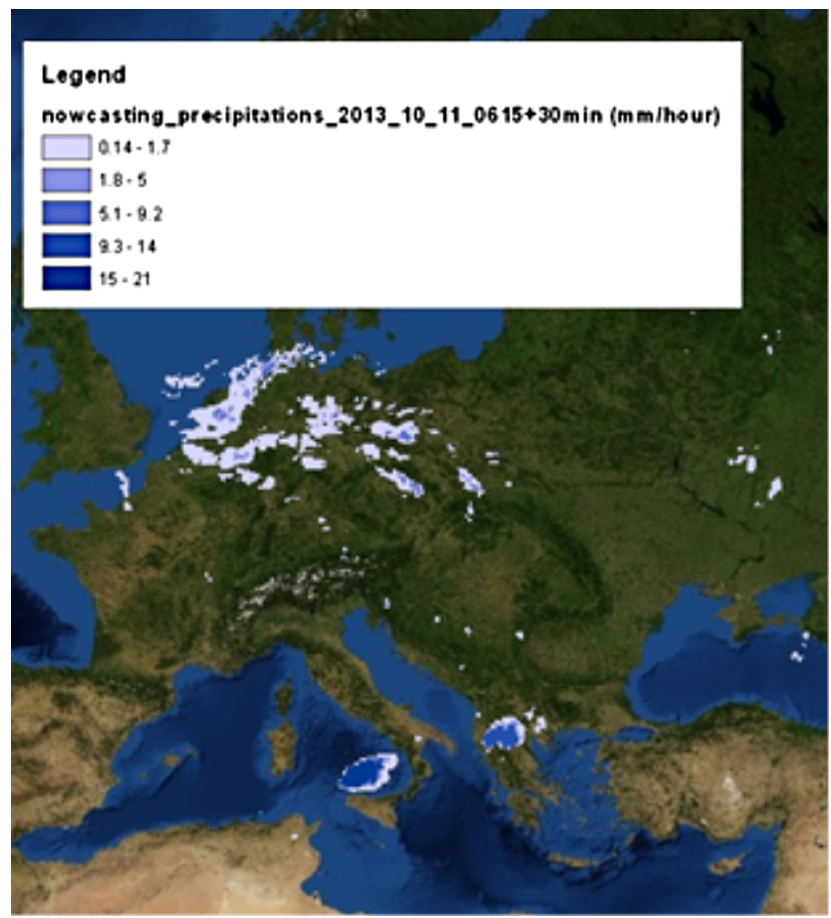

Figure 7. $30 \mathrm{~min}$ precipitation forecast based on MPE of 11 October 2013 06:00 UTC.

\subsection{Graphs and statistics}

The availability of an historical dataset of meteorological data allows MATISSE to provide graphs and statistics de- 


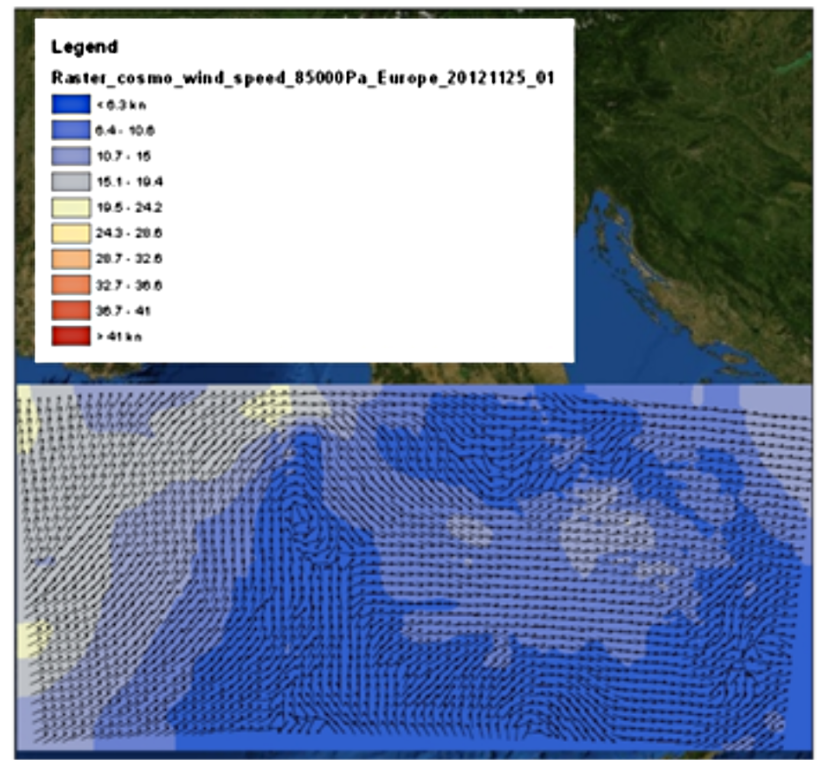

Figure 8. Forecast of wind speeds and directions of 25 November 2012 at 01:00 UTC.

scribing the historical behavior of different meteorological parameters over the main European airports. Users can choose an airport and a period of interest and plot the graph reporting monthly mean, maximum and minimum values of the desired meteorological variable (Fig. 9) or visualize and export the number of occurrences of a parameter below or above a threshold fixed by the user. Another function allows users to compute statistics (mean, variance, maximum, minimum values) of a meteorological parameter over an area of interest by selecting maximum and minimum latitudes and longitudes and a specific time.

Graphs and statistics are all provided to users in text files.

\subsection{Hazard representation for supporting flight management}

In order to support flight management and flight planning tools, MATISSE is equipped with an additional function able to produce text files reporting aviation hazard locations and corresponding hazard levels. In this way the information content to be transmitted on board is drastically reduced, indicating only the latitudes and longitudes of the potentially dangerous areas due to the presence of one or more meteorological hazard. Such information can be fed into onboard Decision Support Systems (DSS): the tool, usually adopted in UAV, to improve on-board situational awareness autonomously.

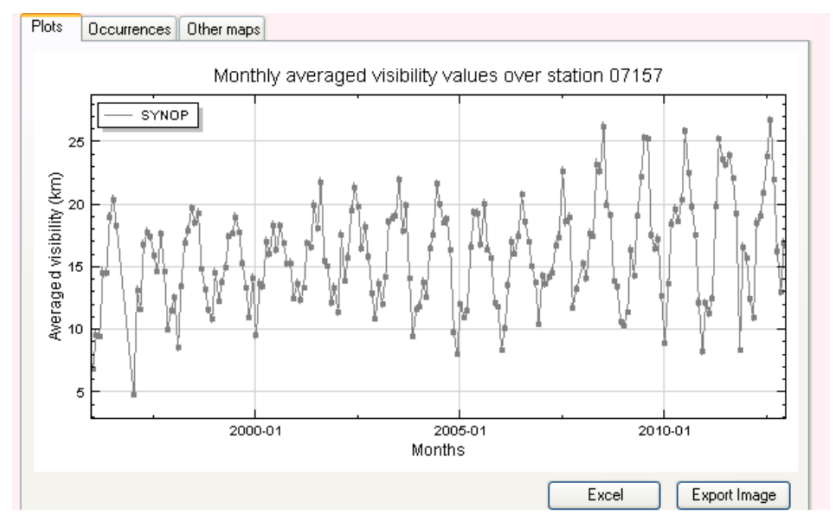

Figure 9. Monthly mean visibility values $(\mathrm{km})$ over Charles de Gaulle airport for period varying from January 1996 to August 2012.

\section{Conclusions}

The MATISSE GIS System described in the present work represents a technology developed to support pilots and automated optimization systems, providing maps, graphs, text files and statistics of observed and forecasted meteorological variables or hazards, in different formats according to different user needs. Meteorological data are displayed in a user-friendly way, indicating the hazard level in order to improve pilots' weather awareness and allowing users to easily identify potentially dangerous areas. Meteorological hazards are reported concisely, providing the relevant information on the hazards present in all the different flight phases. The system is still under development and hence is not currently in use. It will be extended in the future to incorporate additional functions including the forecasting and monitoring of further meteorological hazards and implementing other forecast models (such as ECMWF IFS).

Edited by: T. Hewson

Reviewed by: M. M. Miglietta and another anonymous referee

\section{References}

Austin, G. and Bellon, A.: The use of digital weather radar records for short-term precipitation forecasting, Q. J. Roy. Meteorol. Soc., 100, 658-664, 1974.

Barrere Jr., C. A., Eilts, M., Johnson, J., Fritchie, R., Spencer, P., Shaw, B., Li, Y., Ladwig, W., Schudalla, R., and Mitchell, D.: An Aviation Weather Decision Support System (AWDSS) for the Dubai International Airport, in: 13th Conference on Aviation, Range and Aerospace Meteorology, Amsterdam, the Netherlands, 20-24, 2008.

Carson, C., Thomas, M., Belongie, S., Hellerstein, J. M., and Malik, J.: Blobworld: A system for region-based image indexing and retrieval, in: Visual Information and Information Systems, Springer, 509-517, 1999. 
Doms, G. and Schättler, U.: A description of the nonhydrostatic regional model LM, Deutscher Wetterdienst, Offenbach, Germany, 2002.

EUMETSAT: MSG Level 1.5 Image Data Format Description, https://www.eumetsat.int/website/wcm/idc/idcplg?IdcService= GET_FILE\&dDocName=PDF_TEN_05105_MSG_IMG_ DATA\&RevisionSelectionMethod=LatestReleased $\&$ Rendition $=$ Web (last access date: 6 July 2015), 2007.

EUMETSAT: MSG Meteorological product extraction facility algorithm specification document, Tech. rep., https://www.eumetsat.int/website/wcm/idc/idcplg?IdcService= GET_FILE\&dDocName=PDF_TEN_SPE_04022_MSG_ MPEF\&RevisionSelectionMethod=LatestReleased \&Rendition $=$ Web (last access date: 6 July 2015), 2011.

Gerz, T., Forster, C., and Tafferner, A.: Mitigating the Impact of Adverse Weather on Aviation, in: Atmospheric Physics, Springer, Berlin, Heidelberg, Germany, 645-659, 2012.

Heinemann, T., Latanzio, A., and Roveda, F.: The Eumetsat multisensor precipitation estimate (MPE), in: Second International Precipitation Working group (IPWG) Meeting, Madrid, Spain, 2002.

Hennessy, J.: MARS-The ECMWF Meteorological Archive and Retrieval System, in: Proceedings, 2nd International Conference on Interactive Information and Processing Systems for Meteorology, Oceanography and Hydrology (IIPS), AMS, Miami, Florida, United States, 1986.

Holmlund, K.: Current status of the Eumetsat operational and future AMV extraction facilities, in: Proc, of the 6th Int, Winds Workshop, Madison, 45-52, 2002.

Juga, I. and Vajda, A.: The effect of weather on transportation: assessing the impact thresholds for adverse weather phenomena, in: Proceedings of SIRWEC 16th international road weather conference, Helsinki, Finland, 23-25, 2012.

Krozel, J., McNichols, W., Prete, J., and Lindholm, T.: Causality analysis for aviation weather hazards, in: AIAA Aviation Technology, Integration, and Operations Conf., Anchorage, Alaska, 2008.

Kulesa, G.: Weather and aviation: How does weather affect the safety and operations of airports and aviation, and how does FAA work to manage weather-related effects?, in: The Potential Impacts of Climate Change on Transportation, Transportation Research Board (TRB) and the place is Washington DC, USA, 2003.
Lutz, H.-J., Gustafsson, J. B., and Valenzuela-Leyenda, R.: Scenes and cloud analysis from Meteosat Second generation (MSG) observations, EUMETSAT, EUM, Citeseer, in: Proceedings of the 2003 EUMETSAT Meteorological Satellite Conference, Weimar, Germany, p. P39, 2003.

Puca, S., De Leonibus, L., Zauli, F., Rosci, P., and Biron, D.: Improvements on numerical "object" detection and nowcasting of convective cell with the use of SEVIRI data (IR and WV channels) and neural techniques, in: The World Weather Research Programme's Symposium on Nowcasting and Very Short Range Forecasting, Tolouse, France, 5-9, 2005.

Rillo, V., Manzi, M. P., Mercogliano, P., and Galdi, C.: An advanced platform providing multi-sources aviation-critical weather information, in: IEEE 2014 Metrology for Aerospace (MetroAeroSpace), Benevento, Italy, 484-487, 2014.

Ruokangas, C. C., Mengshoel, O. J., Uckun, S., Rand, T. W., Donohue, P., and Tuvi, S. : Aviation weather awareness and reporting enhancements (AWARE) system using a temporal-spatial weather database and a Bayesian network model, US Patent No. 7081834, Washington, DC, US Patent and Trademark Office, 2006.

Schmetz, J., Pili, P., Tjemkes, S., Just, D., Kerkmann, J., Rota, S., and Ratier, A.: An introduction to Meteosat second generation (MSG), B. Am. Meteorol. Soc., 83, 977-992, 2002.

Snyder, J. and Patsiokas, S.: XM satellite radio-satellite technology meets a real market, in: Proceedings of the 22nd AIAA International Communications Satellite Systems Conference and Exhibit, Monterey, CA, USA, 2004.

Tafferner, A., Forster, C., Sénési, S., Guillou, Y., Tabary, P., Laroche, P., Delannoy, A., Lunnon, B., Turp, D., Hauf, T., and Markovic, D.: Nowcasting thunderstorm hazards for flight operations: the CB WIMS approach in FLYSAFE, in: ICAS2008 Conference, International Council of the Aeronautical Sciences Conf. Proc. (8.6.2), Optimage Ltd., Edinburgh, UK, 1-10, 2008.

Van Eenige, M. J. and Muehlhausen, T.: SPADE: Supporting platform for airport decision-making and efficiency analysis, Proceedings of ICAS 2006, Hamburg, Germany, 2006. 